\title{
Corrosion Resistance of Transmission Pipeline Steel Coated with Five Types of Enamels
}

\author{
Liang Fan ${ }^{1} \cdot$ Fujian Tang ${ }^{1} \cdot$ Signo T. Reis ${ }^{2} \cdot$ Genda Chen $^{1} \cdot$ Michael L. Koenigstein $^{2}$
}

Received: 16 August 2016/Revised: 3 January 2017/Published online: 13 March 2017

(C) The Chinese Society for Metals and Springer-Verlag Berlin Heidelberg 2017

\begin{abstract}
Corrosion is one of the main causes of incidents occurred in hazardous liquid and gas transmission pipelines in the USA, resulting in a loss of over $\$ 12$ billion per year. In this study, the corrosion resistance of pipeline steel coated with five types of enamel was investigated in $3.5 \mathrm{wt} \% \mathrm{NaCl}$ solution with linear polarization resistance and electrochemical impedance spectroscopy tests. Steel coupons were cut from API 5L X65 pipeline steel and coated with five types of enamels using the wet process. The microstructures of all enamel samples were examined by scanning electron microscopy. Experimental results indicate that all enamel coatings increase the corrosion resistance of pipeline steel, and pure enamel PE2, mixed enamels ME1 and ME2 have higher corrosion resistances than pure enamel PE1 and mixed enamel ME3.
\end{abstract}

KEY WORDS: Steel pipe; Enamel coating; Scanning electron microscopy (SEM); Electrochemical impedance spectroscopy (EIS)

\section{Introduction}

Hazardous liquid and gas transmission pipelines in the USA have reached approximately 2.5 million miles. According to the US Department of Transportation, corrosion has become one of the predominant failure causes for hazardous liquid and gas transmission pipelines, which accounts for $24 \%$ of hazardous liquid pipeline incidents

Available online at http://link.springer.com/journal/40195

Genda Chen

gchen@mst.edu

Liang Fan

LF7H2@mst.edu

1 Department of Civil, Architectural, and Environmental Engineering, Missouri University of Science and Technology, Rolla, MO 65409-0030, USA

2 Pro-Perma Engineered Coatings, Roesch Inc., Belleville, IL 62226, USA and $20 \%$ of significant gas transmission pipeline incidents [1].

To combat corrosion and increase service life of pipeline systems, extensive research has been conducted over the past decades, including studies on different corrosion mechanisms, such as carbon dioxide corrosion, hydrogeninduced cracking (HIC), stress corrosion cracking (SSC), microbiologically induced corrosion (MIC) [2-5], and corrosion prevention methods like use of alloy steel, cathodic protection, use of protective coating, and addition of corrosion inhibitors [6-8].

Coating is one of the most effective and efficient methods to protect steel pipeline from corrosion attack. To date, two-part solvent-based epoxy coating, solvent-free and fusion bonding coatings, polyethylene and polyurethane coatings, and glass flake-filled polymeric resin coatings are the main protective barriers to internal corrosion of gas pipelines [9-11]. However, the flowing abrasives in the transmission system can eventually abrade and roughen the surface of these softer organic lining materials and finally the buildup begins. Besides, organic 
coating materials tend to become brittle and separate or delaminate from the base metal because of the leaching or depletion of the oils from the lining materials [12].

Porcelain enamel has been widely used in the industry and sometimes for domestic applications to protect the metals or alloys from corrosion for many years, like chemical reactors, heat exchangers, and food-processing vessels as well as cookware. As an inorganic material, porcelain enamel bonds to the substrate metal by fusing glass frits at $750-850{ }^{\circ} \mathrm{C}$. It can provide a permanent chemical bond in addition to excellent chemical stability, good corrosion resistance, and durability in various harsh environments [13]. During the past 40 years, US Pipe has applied the glass-lined pipe to the wastewater and sewage treatment industry and the enamel coating prevents the interior buildup and clogging of pipe systems successfully [14].

In this study, the electrochemical corrosion behaviors of five types of porcelain enamel-coated pipe were studied with linear polarization resistance (LPR) and electrochemical impedance spectroscopy (EIS) tests. The microstructures of the enamels were also examined to help interpret the electrochemical test results.

\section{Materials and Methods}

\subsection{Sample Preparation}

API 5L X65 steel pipe (MRC Global Inc.) with an outside diameter of $323.850 \mathrm{~mm}$ and a wall thickness of $9.525 \mathrm{~mm}$ was used in this study. The chemical composition of the steel pipe is given in Table 1. The steel coupon samples are coated with two pure enamels (15R-972 and 16R-001) and three mixed enamels. The pure enamels 15R-972 and 16R-001 are designated by PE1 and PE2, respectively. The mixed enamels are designated by ME1, ME2, and ME3, respectively. ME1 was made by mixing $25 \mathrm{wt} \%$ 15R-972 with $75 \mathrm{wt} \%$ 16R-001, ME2 was made by mixing $50 \mathrm{wt} \% 15 \mathrm{R}-$ 972 with 50 wt $\%$ 16R-001, and ME3 was made by mixing $75 \mathrm{wt} \%$ 15R-972 with $25 \mathrm{wt} \%$ 16R-001. The chemical compositions of the pure enamel PE1 (15R-972) and PE2 (16R-001) are listed in Tables 2 and 3, respectively.

Prior to coating, all steel samples were steel-blasted for $1 \mathrm{~min}$ and cleansed with a commercially available cleansing solvent. The glass slurry was applied manually to steel samples using a spray gun. After that, the samples were heated at $150{ }^{\circ} \mathrm{C}$ for $10 \mathrm{~min}$ to drive off moisture, then fired at $840{ }^{\circ} \mathrm{C}$ for $3 \mathrm{~min}$, and finally cooled down to room temperature.

The full-size pipe was cut in longitudinal and circumferential directions into small samples $(25 \mathrm{~mm} \times 50 \mathrm{~mm})$. Each sample was soldered with a copper wire to provide an electrical connection for corrosion tests. All sides of the sample except the front enamel-coated surface were covered with marine epoxy (LOCTITE). As shown in Fig. 1, the uncovered enamel coating area was $20 \mathrm{~mm} \times 30 \mathrm{~mm}$ with an exposed area of $600 \mathrm{~mm}^{2}$.

\subsection{Corrosion Tests}

Electrochemical tests were conducted to understand the corrosion resistances of these five enamel coatings. All samples were immersed in $3.5 \mathrm{wt} \%$ sodium chloride solution, which was prepared by adding purified sodium chloride (Fisher Scientific, Inc.) into distilled water. The samples were tested at room temperature with a typical three-electrode setup, including a $25.4 \mathrm{~mm} \times 25.4 \mathrm{~mm} \times$ $0.254 \mathrm{~mm}$ platinum sheet as a counter electrode, saturated calomel electrode (SCE) as a reference electrode, and the

Table 1 Chemical composition (wt\%) of steel pipe

\begin{tabular}{lllllllllllllll}
\hline $\mathrm{C}$ & $\mathrm{Mn}$ & $\mathrm{P}$ & $\mathrm{S}$ & $\mathrm{Si}$ & $\mathrm{Cu}$ & $\mathrm{Ni}$ & $\mathrm{Cr}$ & $\mathrm{Mo}$ & $\mathrm{Al}$ & $\mathrm{V}$ & $\mathrm{B}$ & $\mathrm{Ti}$ & $\mathrm{Cb}$ & $\mathrm{Fe}$ \\
\hline 0.17 & 1.15 & 0.07 & 0.02 & 0.26 & 0.10 & 0.04 & 0.07 & 0.07 & 0.024 & 0.02 & 0.001 & 0.001 & 0.001 & 98.00 \\
\hline
\end{tabular}

Table 2 Chemical composition (wt\%) of alkali borosilicate glass PE1 (15R-972)

\begin{tabular}{cccccccccccc}
\hline $\mathrm{SiO}_{2}$ & $\mathrm{~B}_{2} \mathrm{O}_{3}$ & $\mathrm{Na}_{2} \mathrm{O}$ & $\mathrm{C}_{\mathrm{a}} \mathrm{O}$ & $\mathrm{M}_{\mathrm{n}} \mathrm{O}_{2}$ & $\mathrm{Al}_{2} \mathrm{O}_{3}$ & $\mathrm{~T}_{\mathrm{i}} \mathrm{O}_{2}$ & $\mathrm{~K}_{2} \mathrm{O}$ & $\mathrm{Fe}_{2} \mathrm{O}_{3}$ & $\mathrm{M}_{\mathrm{g}} \mathrm{O}$ & $\mathrm{P}_{2} \mathrm{O}_{5}$ & $\mathrm{Others}$ \\
\hline 47.73 & 23.17 & 10.6 & 7.58 & 3.58 & 2.16 & 1.92 & 1.25 & 1.12 & 0.41 & 0.39 & 0.09 \\
\hline
\end{tabular}

Table 3 Chemical composition (wt\%) of alkali borosilicate glass PE2 (16R-001)

\begin{tabular}{llllllllllll}
\hline $\mathrm{SiO}_{2}$ & $\mathrm{~B}_{2} \mathrm{O}_{3}$ & $\mathrm{Na}_{2} \mathrm{O}$ & $\mathrm{C}_{\mathrm{a}} \mathrm{O}$ & $\mathrm{M}_{\mathrm{n}} \mathrm{O}_{2}$ & $\mathrm{Al}_{2} \mathrm{O}_{3}$ & $\mathrm{~T}_{\mathrm{i}} \mathrm{O}_{2}$ & $\mathrm{~K}_{2} \mathrm{O}$ & $\mathrm{Fe}_{2} \mathrm{O}_{3}$ & $\mathrm{M}_{\mathrm{g}} \mathrm{O}$ & $\mathrm{P}_{2} \mathrm{O}_{5}$ & $\mathrm{Others}$ \\
\hline 56.13 & 19.37 & 6.34 & 5.67 & 0.60 & 6.05 & 4.38 & 0.48 & 0.45 & 0.40 & 0.05 & 0.08 \\
\hline
\end{tabular}




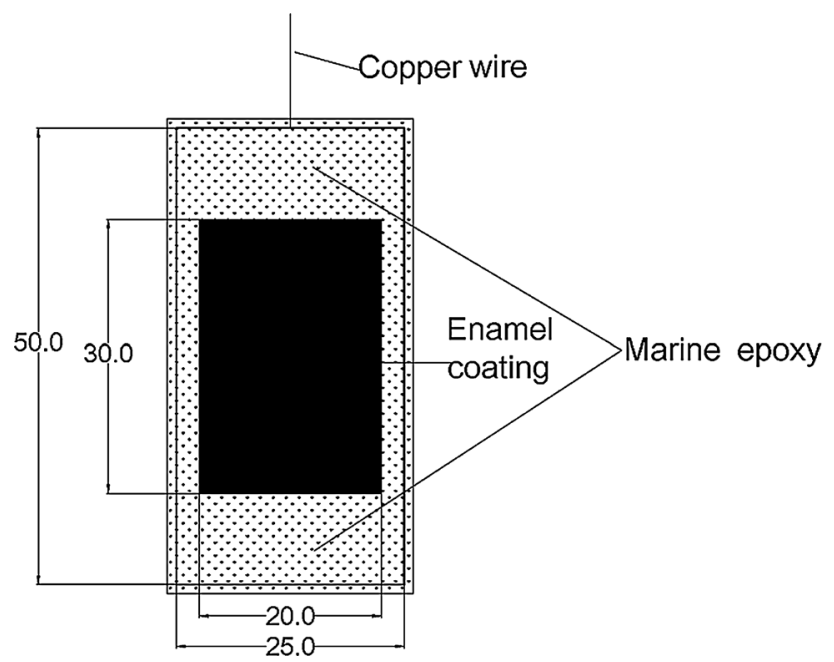

Fig. 1 Test sample dimension (unit: $\mathrm{mm}$ )

sample as a working electrode. All three electrodes were connected to a Gamry, Interface 1000E Potentiostat for data acquisition. Before LPR and EIS tests, a stable corrosion potential was obtained by immersing the specimens in the sodium chloride solution for about $1.0 \mathrm{~h}$. Then, the linear polarization resistance (LPR) curves were measured within $15 \mathrm{mV}$ around the corrosion potential at a scan rate of $0.167 \mathrm{mV} / \mathrm{s}$. Afterward, the EIS test, which is used to study the resistance of the coating to corrosion, was conducted at ten points per decade around the corrosion potential, with a sinusoidal potential wave of $10 \mathrm{mV}$ in amplitude and a frequency ranging from $100 \mathrm{kHz}$ to $5 \mathrm{MHz}$. For each coating type, three samples were prepared and tested, and only the results of representative samples were demonstrated in this paper.

\subsection{Coating Characterization}

To examine the microstructure of each coating, enamelcoated samples were cold-mounted in epoxy resin (EpoxyMount, Allied High Tech Products, Inc.). Each one was cut into a 10.0-mm-thick cross section using a diamond saw. The 10.0-mm-thick slice samples were abraded with silicon carbide papers with grits of $80,180,320,600,800$, and 1200. After abrading, all samples were rinsed with deionized water and dried in air at room temperature. The microstructure of each sample was examined by scanning electron microscopy (SEM, Hitachi S-4700, Tokyo).

\subsection{Visual Observation After Corrosion Tests}

After corrosion tests, the samples were taken out of the sodium chloride solution and washed with distilled water, and then were dried at room temperature. After drying, the surface conditions on enamel-coated samples especially the samples with small corrosion products were examined.

\section{Results and Discussion}

\subsection{Coating Microstructure and Visual Observation After Tests}

Cross-sectional SEM images of five enamel-coated steel samples are presented in Fig. 2. The thicknesses of enamel coating PE1, PE2, ME1, ME2, and ME3 are approximately 250, 363, 227, 159, and $409 \mu \mathrm{m}$, respectively. The air bubbles observed in the enamel coatings were released from the high-temperature chemical reaction of the enamel with the steel substrate during enameling process. All the enamel coatings have numerous isolated small pores and a few large pores except that coating PE1 does not have large pores. Enamel coating PE2 has the fewest number of small air bubbles but has a few huge air bubbles with a diameter of around $220 \mu \mathrm{m}$, which is almost the same as the thickness of the coating ME2. Besides, mixed enamels ME1, ME2, and ME3 have some large air bubbles with the diameter around $90 \mu \mathrm{m}$.

After corrosion tests, the surface conditions of all samples were examined visually. No corrosion was observed on the surface of PE2, ME1, and ME2 coatings. However, some tiny corrosion spots could be observed on PE1- and ME3-coated samples. Figure 3 shows the surface conditions of PE1- and ME3-coated steel samples. As can be observed, some very tiny corrosion spots with small corrosion products can be observed on the surface. This is probably due to the coating damage/defects, allowing sodium chloride solution to penetrate and react with substrate steel.

\subsection{Linear Polarization Resistance}

The linear polarization resistance plots of the five kinds of enamel-coated samples and uncoated steel sample are shown in Fig. 4. It is noted that the horizontal electrical currents have different units $(\mu \mathrm{A}, \mathrm{nA}, \mathrm{pA})$ and are not normalized by the total surface area.

The polarization resistance $R_{\mathrm{p}}$ is equal to the slope of the linear region of the polarization curve around the zero current [15]:

$R_{\mathrm{p}}=\Delta E / \Delta I$.

Then, the corrosion current density can be calculated by

$i_{\text {corr }}=B /\left(A R_{\mathrm{p}}\right)$,

where $i_{\text {corr }}$ is the corrosion current density, $B$ is a constant related to the Tafel constants $(B=26 \mathrm{mV}$ was used in this 


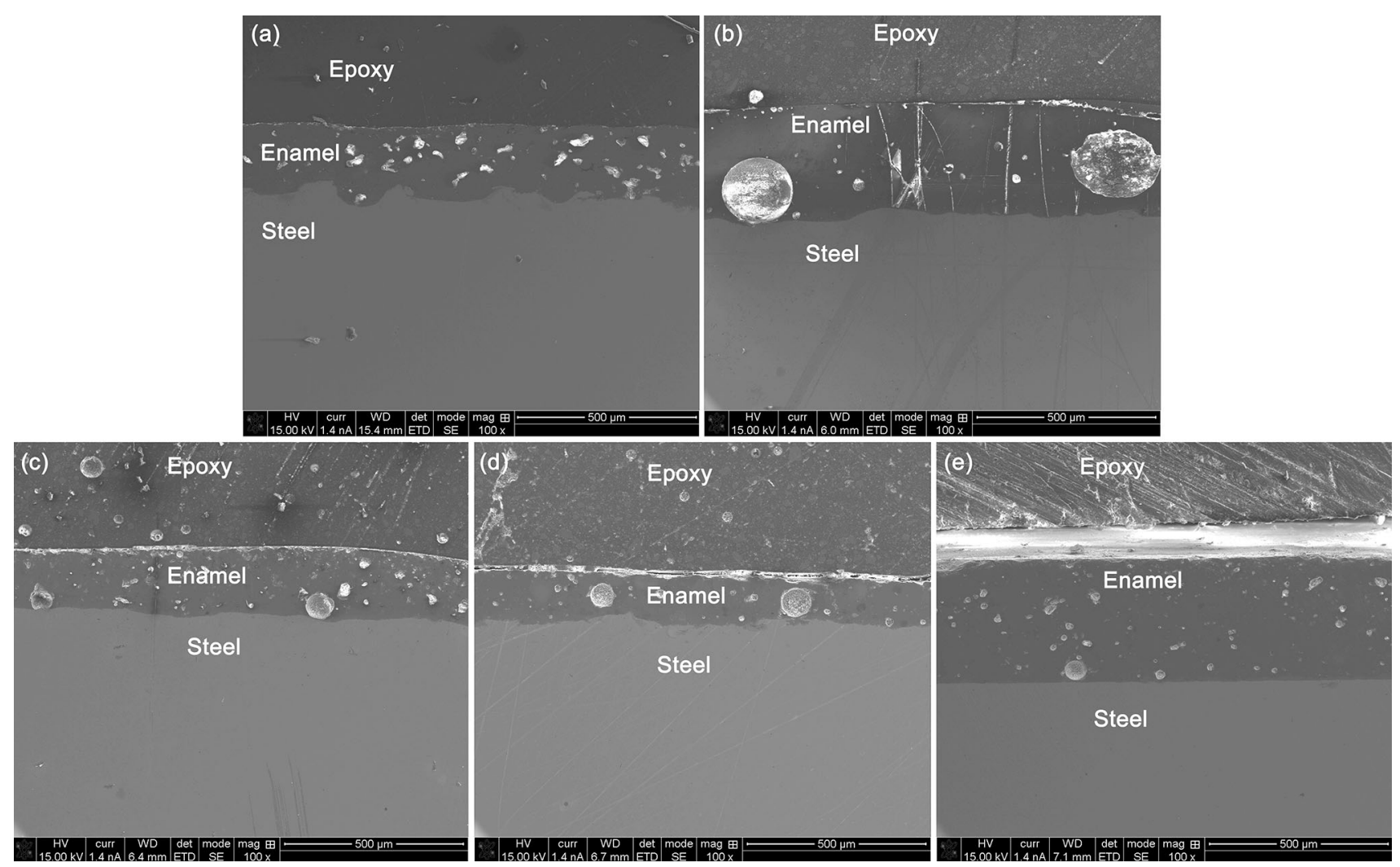

Fig. 2 SEM images of: a PE1-, b PE2-, c ME1-, d ME2-, e ME3-coated steel samples

(a)

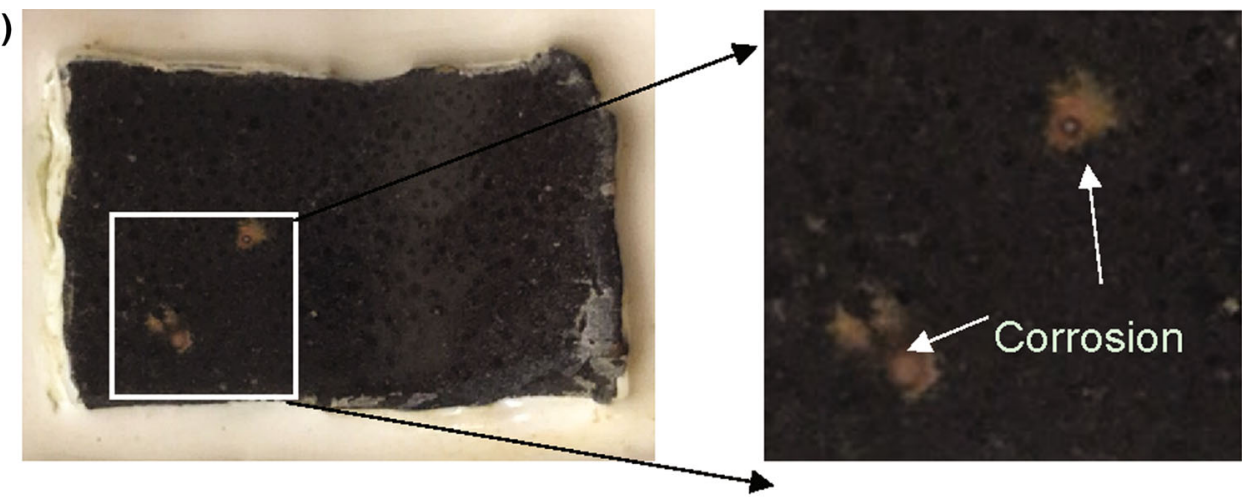

(b)

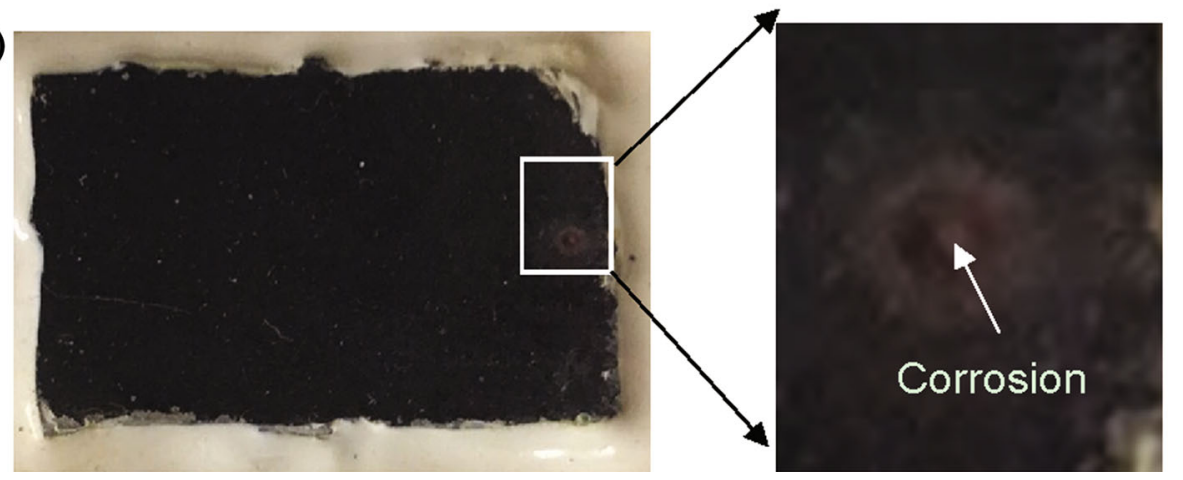

Fig. 3 Surface conditions of: a PE1-, b ME3-coated steel samples 

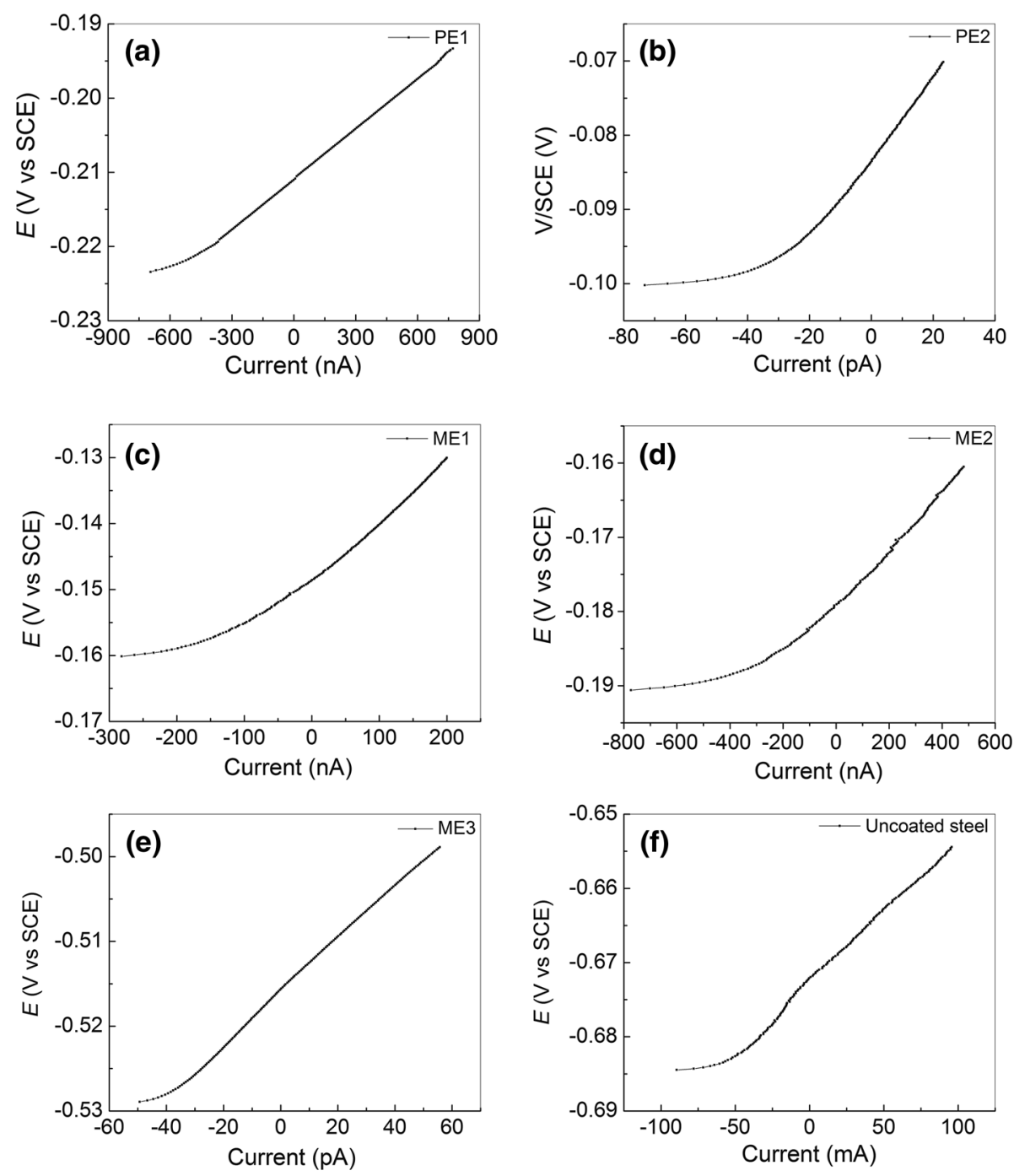

Fig. 4 Polarization resistance plots for: a Enamel 15R-972(PE1)-, b Enamel 16R-001(PE2)-, c Enamel 25 wt\% $15 \mathrm{R}-972$ and 75 wt\% 16R001(ME1)-, d Enamel 50 wt\% 15R-972 and 50 wt\% 16R-001(ME2)-, e 75 wt\% 15R-972 and 25 wt\% 16R-001(ME3)-coated, f uncoated steel samples

study [15]), and $A$ is the exposed sample area. The corrosion current density can be converted into corrosion rate:

Corrosion rate $=\frac{i_{\text {corr } M}}{\rho n F}$,

where $M$ is the molar mass of iron $(55.85 \mathrm{~g}), n$ is the valency number of iron (2), $\rho$ is density of the iron $(7.88 \mathrm{~g} /$ $\left.\mathrm{cm}^{3}\right)$, and $F$ is Faraday's constant $(96,485 \mathrm{C} / \mathrm{mol})$. The corrosion potential, polarization resistance, and corrosion rates of the tested samples are listed in Table 4.

The corrosion potential of uncoated steel sample is around $-0.69 \mathrm{~V}$ versus SCE, indicating an active corrosion. This is also confirmed by the high corrosion rate with a value of $0.24 \mathrm{~mm} / \mathrm{year}$. Among the two pure enamel coatings, PE2 has a higher corrosion potential, a higher polarization resistance, and a lower corrosion rate than PE1. The corrosion rate of PE2 is almost $10^{5}$ order lower than PE1. Mixed enamels also demonstrated quite different corrosion behaviors. ME1 and ME2 are much better than ME3. The corrosion rate of ME3-coated sample is $10^{2}-10^{3}$ lower than those with ME1 and ME2 coatings. The lower corrosion resistances of PE1 and ME3, compared with their peer samples, are probably because there are some more damage or coating defects present on the PE1- and ME3coated samples [16]. The coating damage or defects provide pathways for sodium chloride penetration, resulting in reduced corrosion resistance.

Based on the corrosion rates, the corrosion resistances of all the five enamel coatings can be ranked as follows: PE2 $>$ ME1 $>$ ME2 $>$ ME3 $>$ PE1. However, all the enamel-coated samples have much lower corrosion rates 
Table 4 Polarization resistance and corrosion rates of five different enamel-coated samples

\begin{tabular}{lllllll}
\hline & PE1 & PE2 & ME1 & ME2 & ME3 & Uncoated \\
\hline Ecorr (V vs SCE) & -0.208 & -0.085 & -0.145 & -0.175 & -0.513 \\
$R_{\mathrm{p}}(\Omega)$ & $2.17 \times 10^{4}$ & $8.20 \times 10^{8}$ & $8.93 \times 10^{7}$ & $2.34 \times 10^{7}$ & $3.76 \times 10^{5}$ & $2.68 \times 10^{2}$ \\
Corrosion rate (mm/year) & $2.15 \times 10^{-4}$ & $8.96 \times 10^{-8}$ & $6.47 \times 10^{-7}$ & $1.46 \times 10^{-6}$ & $1.55 \times 10^{-4}$ & 0.24 \\
\hline
\end{tabular}

than uncoated steel samples, which indicates that all the enamel-coated samples can prevent the steel from corrosion to some extents.

\subsection{Impedance Spectrum}

The electrochemical impedance spectra of samples coated with five different enamels and the uncoated sample are presented in the format of Nyquist and Bode plots in Fig. 5. The Nyquist plot of PE1-coated sample shows two separated semi-circles with a diffusion tail. Only one big semicircle is observed for PE2-, ME1-, ME2-, and ME3-coated samples. This is likely because the two time constants corresponding to electrochemical reactions at the steel/electrolyte interface and the dielectric properties of enamel coating are overlapped [17]. However, two phase angle maxima in the low- and high-frequency ranges can be clearly seen from the phase angle-frequency diagrams of PE2-, ME1-, ME2-, and ME3-coated samples, which correspond to the two time constants [18-20]. Uncoated steel sample showed one capacitive loop and one phase angle maxima in the low-frequency range. This means that only one time constant appears, which corresponds to the electrochemical reactions at the steel/electrolyte interface. The PE2-coated sample shows up to 5 orders of magnitude higher impedance modulus than PE1- and ME3-coated samples, reaching almost $1 \mathrm{G} \Omega \mathrm{cm}^{2}$. The phase angles at $100 \mathrm{kHz}$ of PE1-, PE2-, ME1-, ME2-, and ME3-coated samples are around $60^{\circ}, 90^{\circ}, 80^{\circ}, 60^{\circ}$, and $40^{\circ}$, respectively. The higher phase angle of approximate $90^{\circ}$ means that the enamel coating can provide good corrosion protection, and the lower phase angle indicates that the electrolyte has a large potential to penetrate through the coating, which will increase the coating capacitance [21]. All the enamel-coated samples have much higher impedance values than the uncoated steel.

Three electrical equivalent circuit (EEC) models are chosen to fit the experimental data [18-20]. In the EIS diagrams as shown in Fig. 5, the dotted points are the experimental data and the solid lines represent curve fitting by EEC models. The Warburg impedance $W$ is included in model (c) to simulate the diffusion behavior, which is caused by the accumulation of corrosion products at sites with coating damage or defect. The three EEC models are illustrated in Fig. 6. Model (a), model (b), and model (c) were used to simulate the uncoated sample, PE2-, ME1, and ME3-coated samples, and PE1- and ME2-coated samples, respectively. The difference between model (b) and model (c) is the diffusion impedance, which is associated with the oxygen diffusion through corrosion products. As mentioned before, some damage/defects may be present on the coatings, which would form pathways for penetration of sodium chloride solution. Once the solution penetrated through these pathways to the substrate steel surface, corrosion would occur and corrosion products would be generated. The corrosion products would accumulate at these damage/defect sites, and consequently, oxygen needed for the corrosion reaction had to diffuse through these corrosion products to participate in the corrosion reaction at the exposed steel surface.

Specifically, in these models, $R_{\mathrm{s}}$ represents the solution resistance, $\mathrm{CPE}_{\mathrm{c}}$ represents coating capacitance, $R_{\mathrm{c}}$ represents coating resistance, $\mathrm{CPE}_{\mathrm{dl}}$ represents double-layer capacitance, and $R_{\mathrm{ct}}$ represents the charge transfer resistance, $\mathrm{CPE}_{\mathrm{c}}$ is used to replace pure capacitance because of non-homogeneity in thickness and roughness of the coating $[22,23] . \mathrm{CPE}_{\mathrm{dl}}$ represents a certain deviation extent from the pure capacitance due to a distribution of reactivity [24]. A CPE is defined by two parameters $Y$ and $n$, and its impedance is represented by:

$Z_{\mathrm{CPE}}=Y^{-1}(j w)^{-n}$,

where $Y$ is a parameter with dimension of $\Omega \mathrm{s}^{n} / \mathrm{cm}^{2}$, which is proportional to the pure capacitance, $\omega$ is the angular frequency in $\operatorname{rad~s}^{-1}$, and $n$ is an index that represents the deviation from a pure capacitor $[18,25]$. For $n=1, \mathrm{CPE}$ resembles a pure capacitor with capacitance $Y$. For $n=0$, CPE represents a resistor with resistance $Y^{-1}$. The effective capacitance based on CPE parameters can be obtained by $[26,27]$ :

$C=Y^{1 / n} R^{(1-n) / n}$,

where parameters $R_{\mathrm{c}}, Y_{\mathrm{c}}$, and $n_{\mathrm{c}}$ are used to calculate the effective capacitance of enamel coatings $C_{\mathrm{c}} ; R_{\mathrm{ct}}, Y_{\mathrm{dl}}$, and $n_{\mathrm{dl}}$ are used to calculate the effective capacitance of double layer $C_{\mathrm{dl}}$.

ZSimpWin was used to fit the EIS data with the two EEC models as shown in Fig. 5. The Chi-squared values 

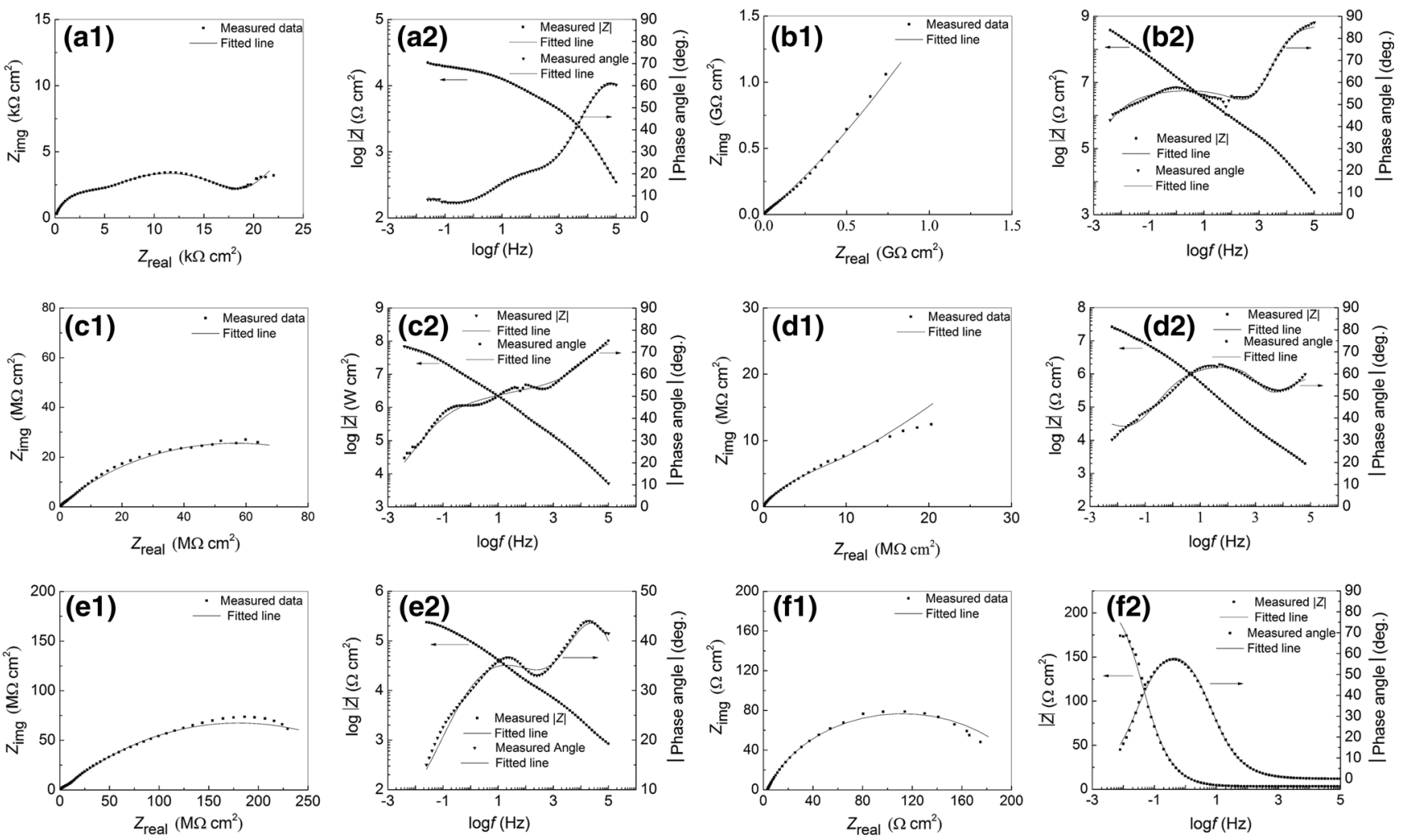

Fig. 5 EIS diagrams (1: Nyquist plot; 2: Bode plot) for: a Enamel 15R-972 (PE1)-, b Enamel 16R-001 (PE2)-, c Enamel 25 wt\% 15R-972 and $75 \mathrm{wt} \%$ 16R-001(ME1)-, d Enamel $50 \mathrm{wt} \%$ 15R-972 and $50 \mathrm{wt} \%$ 16R-001(ME2)-, e $75 \mathrm{wt} \%$ 15R-972 and 25 wt\% 16R-001(ME3)-coated, f uncoated steel samples

(a)

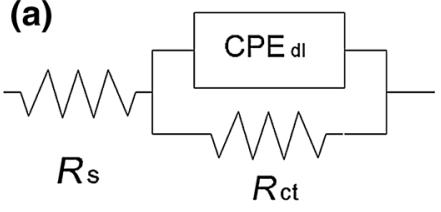

(b)

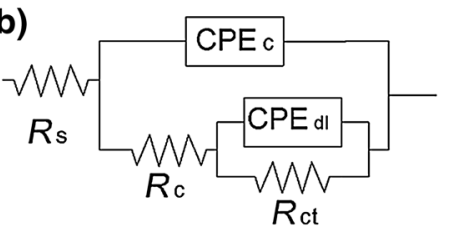

(c)

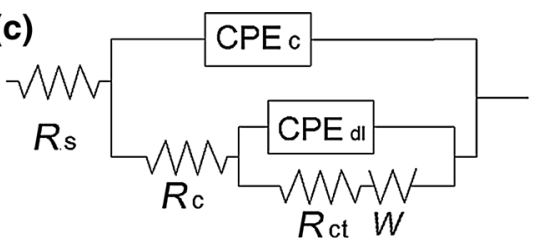

Fig. 6 EEC models for: a uncoated; b PE2-, ME1-, and ME3-, c PE1- and ME2-coated samples

are in the order of $10^{-4}-10^{-3}$, indicating a satisfactory fitting process. The parameters obtained from fitting the EEC models are listed in Table 5.

In general, the coating resistance measures the barrier performance of a coating against electrolyte penetration, and the coating capacitance indicates the diffusion of electrolyte solution into the coating. Both parameters are closely related to the dielectric property, microstructure, thickness, and defect of the coating itself. The PE2 coating has the highest coating resistance and the lowest capacitance, which means higher electrolyte penetrating resistance and lower electrolyte diffusion into coating, respectively. The PE1 coating and ME3 coating have the lowest coating resistance and relatively higher coating capacitance, which provide the least protection from chloride attack.
The charge transfer resistance measures the ease of electron transfer across the metal surface, which is inversely proportional to corrosion rate [28]. Uncoated steel sample has the lowest charge transfer resistance $217 \Omega \mathrm{cm}^{2}$ and the highest double-layer capacitance $0.025 \mathrm{~F} / \mathrm{cm}^{2}$. The PE2 coating has the highest charge transfer resistance with the value of $1.35 \times 10^{9} \Omega \mathrm{cm}^{2}$ is five orders of magnitude larger than that of coating PE1, and quite close to the $R_{\mathrm{p}}$ from linear polarization resistance test. The double-layer capacitance $C_{\mathrm{dl}}$, calculated from Eq. (5), is also a measure of ease of charge transfer. The lower double-layer capacitance values of coatings PE2, ME1, and ME2 indicate better corrosion performance compared with coatings PE1 and ME3. The higher charge transfer resistance and lower double-layer capacitance of coating PE2 show better resistance to the transfer of electrons across the metal 
Table 5 EEC parameters obtained by fitting with experimental data

\begin{tabular}{|c|c|c|c|c|c|c|c|c|}
\hline & $Y_{\mathrm{c}}\left(\Omega \mathrm{s}^{n} / \mathrm{cm}^{2}\right)$ & $n_{\mathrm{c}}$ & $R_{\mathrm{c}}\left(\Omega \mathrm{cm}^{2}\right)$ & $C_{\mathrm{c}}\left(\mathrm{F} / \mathrm{cm}^{2}\right)$ & $Y_{\mathrm{dl}}\left(\Omega \mathrm{s}^{n} / \mathrm{cm}^{2}\right)$ & $n_{\mathrm{dl}}$ & $R_{\mathrm{ct}}\left(\Omega \mathrm{cm}^{2}\right)$ & $C_{\mathrm{dl}}\left(\mathrm{F} / \mathrm{cm}^{2}\right)$ \\
\hline PE1 & $9.44 \times 10^{-8}$ & 0.78 & $4.24 \times 10^{3}$ & $9.74 \times 10^{-9}$ & $7.65 \times 10^{-6}$ & 0.49 & $1.51 \times 10^{4}$ & $7.95 \times 10^{-7}$ \\
\hline PE2 & $6.10 \times 10^{-10}$ & 0.96 & $2.72 \times 10^{5}$ & $3.89 \times 10^{-10}$ & $2.09 \times 10^{-8}$ & 0.62 & $1.35 \times 10^{9}$ & $1.62 \times 10^{-7}$ \\
\hline ME1 & $2.05 \times 10^{-9}$ & 0.86 & $6.27 \times 10^{4}$ & $4.65 \times 10^{-10}$ & $4.55 \times 10^{-8}$ & 0.53 & $1.14 \times 10^{8}$ & $1.93 \times 10^{-7}$ \\
\hline ME2 & $8.64 \times 10^{-8}$ & 0.67 & $3.06 \times 10^{4}$ & $1.47 \times 10^{-8}$ & $1.25 \times 10^{-8}$ & 0.84 & $1.35 \times 10^{7}$ & $8.00 \times 10^{-9}$ \\
\hline ME3 & $2.61 \times 10^{-7}$ & 0.65 & $7.31 \times 10^{3}$ & $8.72 \times 10^{-9}$ & $3.44 \times 10^{-6}$ & 0.45 & $3.51 \times 10^{5}$ & $3.60 \times 10^{-6}$ \\
\hline Uncoated & - & - & - & - & $1.71 \times 10^{-2}$ & 0.78 & 217 & 0.025 \\
\hline
\end{tabular}

surface $[25,29]$. The index $n_{\mathrm{c}}$ of coating PE2 is 0.957 , which means the coating is quite close to pure capacitor property. However, the index $n_{c}$ of coating ME3 (=0.648) is the smallest, indicating the great non-homogeneity property of this coating. The corrosion resistance ranking for all five enamel coatings obtained from this EIS results is the same as that from LPR tests.

\section{Conclusions}

Based on the experimental results and analysis, the following conclusion can be drawn:

1. The tested enamel coatings vary from 160 to $410 \mu \mathrm{m}$ thick, containing numerous isolated small pores and large air bubbles, which was generated during the enameling process.

2. Linear polarization resistance test results are consistent with EIS results. The corrosion rates of the steel samples coated with PE1 and ME3 are $2.15 \times 10^{-4}$ $\mathrm{mm} /$ year and $1.55 \times 10^{-4} \mathrm{~mm} /$ year, respectively, which are higher than those coated with PE2, ME1, and ME2. EIS results also show that PE1 and ME3 have lower coating resistance and higher coating capacitance, as well as lower charge transfer resistance and higher double-layer capacitance in sodium chloride solution than the rest enamel coatings.

3. All five enamel coatings increase the corrosion resistance of pipeline steel. The corrosion resistances for all five enamel coatings are ranked as: PE2 $>$ ME1 $>$ ME2 $>$ ME3 $>$ PE1. The poor corrosion resistances of PE1 and ME3 coatings are most likely attributed to coating damage and defects, which provides pathways for electrolyte penetration.

Acknowledgements The authors gratefully acknowledge the financial support provided by the US Department of Transportation under Award No. DTPH5615HCAP10. The findings and opinions expressed in this paper are those of the authors only and do not necessarily reflect the views of the sponsor.

\section{References}

[1] The state of the national pipeline infrastructure, US Department of Transportation

[2] Z. Liu, X. Gao, C. Yu, L. Du, J. Li, P. Hao, Acta Metall. Sin. (Engl. Lett.) 28, 6 (2015)

[3] X. Shi, Y. Wei, W. Wang, L. Zhao, Y. Shan, K. Yang, Acta Metall. Sin. (Engl. Lett.) 28, 7 (2015)

[4] L. Fan, Z. Liu, W. Guo, J. Hou, C. Du, X. Li, Acta Metall. Sin. (Engl. Lett.) 28, 7 (2015)

[5] T. Wu, M. Yan, D. Zeng, J. Xu, C. Yu, C. Sun, W. Ke, Acta Metall. Sin. (Engl. Lett.) 28, 1 (2015)

[6] S. Ranade, M. Forsyth, M.Y.J. Tan, Prog. Org. Coat. 101, 111 (2016)

[7] W. Wang, Q. Wang, C. Wang, J. Yi, J. Loss Prev. Process Ind. 29, 163 (2014)

[8] O. Martínez, M. Elena, J.M. Flores, J. Genesca, J. Loss Prev. Process Ind. 35, 19 (2015)

[9] Y. Charron, S. Duval, D. Melot, S. Shaw, V. Alary, Designing for internally coated pipelines, in The 16th International Conference on Pipeline Protection, Paphos, Cyprus, 2-4 November 2005

[10] L.T. Pretorius, New application technology for internal pipeline coatings in situ pipeline protection using pigging techniques, in The NACE International Corrosion Conference, San Diego, California, 12-16 March 2006

[11] R.S. Lauer, The use of high performance polymeric coatings to mitigate corrosion and deposit formation in pipeline applications, in The NACE International Corrosion Conference, Nashville, Tennessee, 11-15 March 2007

[12] U.S. Pipe. http://www.uspipe.com/u-s-pipe-fabrication/products/ specialty-lining-coatings/glass-lining-porcelain-enamel

[13] V. Hock, S. Morefield, D. Day, C. Weiss, P. Malone, The use of vitreous enamel coatings to improve bonding and reduce corrosion in concrete reinforcing steel, in The NACE International Corrosion Conference, New Orleans, Louisiana, 16-20 March 2008

[14] S. Rossi, N. Parziani, C. Zanella, Wear 332-333, 702 (2015)

[15] F. Tang, G. Chen, J.S. Volz, R.K. Brow, M.L. Koenigstein, Cem. Concr. Compos. 35, 171 (2013)

[16] E. Sadeghimeresht, N. Markocsan, P. Nylén, Coatings 6, 2 (2016)

[17] G.W. Walter, Corros. Sci. 26, 9 (1986)

[18] F. Tang, G. Chen, J.S. Volz, R.K. Brow, M. Koenigstein, Constr. Build. Mater. 35, 376 (2012)

[19] S.V. Harb, F.C. dos Santos, B.L. Caetano, S.H. Pulcinelli, C.V. Santilli, P. Hammer, RSC Adv. 5, 20 (2015)

[20] C. Zhu, R. Xie, J. Xue, L. Song, Electrochim. Acta 56, 16 (2011)

[21] Y. Zuo, R. Pang, W. Li, J.P. Xiong, Y.M. Tang, Corros. Sci. 50, $12(2008)$ 
[22] M.J.R. Presa, R.I. Tucceri, M.I. Florit, D. Posadas, J. Electroanal. Chem. 502, 1 (2001)

[23] Z. Yao, Z. Jiang, F. Wang, Electrochim. Acta 52, 13 (2007)

[24] E.O. Mark, T. Bernard, Electrochemical Impedance Spectroscopy (Wiley-Interscience, New York, 2008), p. 233

[25] F. Tang, X. Cheng, G. Chen, R.K. Brow, J.S. Volz, M.L. Koenigstein, Electrochim. Acta 92, 36 (2013)
[26] B. Hirschorn, M.E. Orazem, B. Tribollet, V. Vivier, I. Frateur, M. Musiani, Electrochim. Acta 55, 21 (2010)

[27] P. Córdoba-Torres, T.J. Mesquita, O. Devos, B. Tribollet, V. Roche, R.P. Nogueira, Electrochim. Acta 72, 172-178 (2012)

[28] H.H. Hassan, E. Abdelghani, M.A. Amin, Electrochim. Acta 52, 22 (2007)

[29] X. Liu, J. Xiong, Y. Lv, Y. Zuo, Prog. Org. Coat. 64, 4 (2009) 